DOI: http://doi.org/10.21698/simi.2017.0001

\title{
HYBRID SONOLYSIS APPLICATION AS POLISHING STEP FOR REMOVAL OF THMS GENERATED FROM THE DRINKING WATER TREATMENT
}

Mihai Stefanescu, Ionut Cristea, Cristiana Cosma

National Research and Development Institute for Industrial Ecology ECOIND, 71-73 Drumul Podu Dambovitei, 060652, Bucharest, Romania, tehnologi@incdecoind.ro

\begin{abstract}
Trihalomethanes (THMs) are organic compounds (with toxicity potential) generated during the classical treatment flow of drinking water as a result of reaction between natural organic matter (always present in drinking waters resources) and chlorine, which is the most disinfection reagent on a broad scale, in drinking water treatment plants. Ultrasonic treatment can be feasible for THMs removal for small or medium drinking water treatment plants.

This paper emphasyzes the possiblity to use sonolysis (chemical oxidation based on active radicals generated during cavitation process) as polishing step in drinking water treatment flow for trihalomethanes (THMs - trichloromethane, tribromomethane and bromodichloromethane) removal (initial concentrations over the admitted limit - 100 $\mu \mathrm{g}$ THM/1).

Four sonolysis systems were tested for synthetic and real surface treated water: direct sonolysis (US), $\mathrm{US}+\mathrm{H}_{2} \mathrm{O}_{2}$, $\mathrm{US}+\mathrm{H}_{2} \mathrm{O}_{2}+\mathrm{Fe}$ (Fenton sonolysis), $\mathrm{US}+\mathrm{H}_{2} \mathrm{O}_{2}+\mathrm{Fe}+$ UV (low pressure mercury lamp $\lambda=250-400 \mathrm{~nm}$ ). The variation domains of the main process parameters were as following: THMs concentrations $310 \div 3615 \mu \mathrm{g} / \mathrm{L}$, sonolysis time $1 \div 60 \mathrm{~min}$, ultrasonic energy $2 \times 10^{6} \mathrm{~J}-8 \times 10^{6} \mathrm{~J}$, ultrasonic amplitude $20 \div 80 \%$, oxidant dose $0.6 \div 2.1 \mathrm{~g} \mathrm{H}_{2} \mathrm{O}_{2} / \mathrm{L}$, catalyst dose $0.25 \div 2 \mathrm{mg} \mathrm{Fe}^{2+} / \mathrm{L}$.

Experimental results showed the evolution of THMs removal depending on sonolysis system: direct sonolysis (US) $56 \%<$ sonolysis and hidrogen peroxide (US $+\mathrm{H}_{2} \mathrm{O}_{2}$ ) $59 \%<$ foto Fenton sonolysis (US $+\mathrm{H}_{2} \mathrm{O}_{2}+\mathrm{Fe}+\mathrm{UV}$ ) $63 \%<$ Fenton sonolysis (US + $\left.\mathrm{H}_{2} \mathrm{O}_{2}+\mathrm{Fe}\right) 73 \%$ emphasizing that bromoform are more difficult to remove compared to other.
\end{abstract}

Keywords: cavitation, drinking water, direct sonolysis, hybrid sonolysis, THMs

\section{Introduction}

Ultrasonic radiation is a vibration of an elastic medium (water, gases, solids) having over $16 \mathrm{kHz}$ frequency with many application in medicine, industry, biology as well as in water/wastewater treatment (Ashokkumar 2011).

Since 1990s ultrasound has been widely used in water and wastewater treatment processes as an emerging advanced oxidation process (AOP) technology, applicable for a wide range of contaminants with various initial concentrations (Mahammumi \& Adewuyi 2010).

Generation, combination and recombination of free radicals, very reactive, able to degrade pollutants from water are the base of aqueous solutions sonochemistry (Ashokkumar 2011; Mahammumi \& Adewuyi 2010; Naddeo \& Belgiornao 2007).

Scientifically research in this field proved that direct sonolysis is efficient for 


\section{INTERNATIONAL SYMPOSIUM "THE ENVIRONMENT AND THE INDUSTRY", SIMI 2017, PROCEEDINGS BOOK}

advanced degradation of organic pollutants in water. Ultrasounds become more efficient in both pollutants degradation and economical if sonolyse is associated with other classical and AOPs methods for water treatment: $\mathrm{US}+\mathrm{H}_{2} \mathrm{O}_{2}, \mathrm{US}+\mathrm{H}_{2} \mathrm{O}_{2}+\mathrm{Fe}$, $\mathrm{US}+\mathrm{O}_{3}$, US + UV, US + electrochemical oxidation, US + adsorption (Joseph et al. 2009).

Natural organic matter from drinking water sources reacts with chlorine generating THMs. Over the limit of $100 \mu \mathrm{g} / \mathrm{L}$ THMs became toxic for human so, should be avoided their generation and diminished the concentrations below admitted limit if their formation cannot be prevented (Shemmer \& Narkis 2005; Stefanescu et al. 2015).

Chlorine is still the most efficient and economical disinfectant having remanence in drinking water pipes. Because of this last reason chlorine cannot be totally replaced by ozone or/and UV radiation in the drinking water treatment plants.

Sonolysis could be an alternative option for THMs advanced removal from drinking water.

\section{Experimental}

This paper emphasizes the possibility to use sonolysis (chemical oxidation based on active radicals generated during cavitation process) as polishing step in drinking water treatment flow for trihalomethanes (THMs) removal (concentrations over the admitted limit - $100 \mu \mathrm{g}$ THM/L).

Fig. 1 and Fig. 2 show the ultrasonic reactor (SONICS Vibracell 500) and photolytic reactor (Haereus) respectively which are used in sonolysis and hybrid sonolysis tests.

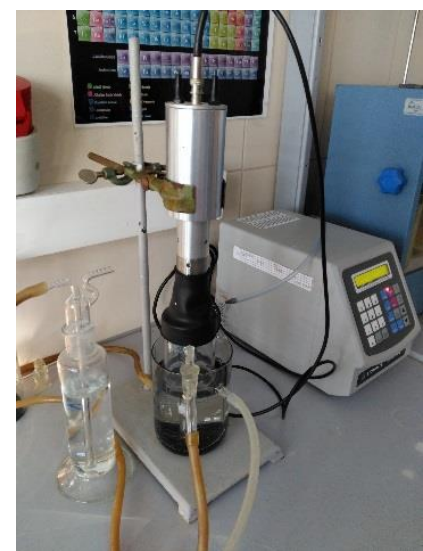

Figure 1. Ultrasonic reactor

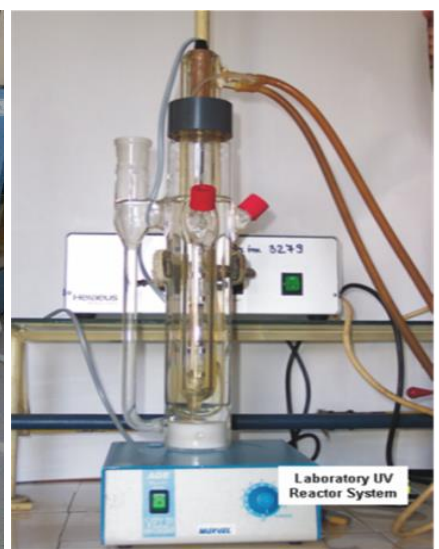

Figure 2. UV Reactor

Preliminary experimental tests were performed on synthetic water (deionized water and THMs dosage: trichloromethane, tribromomethane and bromodichloromethane) in order to establish the influence of THMs initial concentration, type of sonolyse system, ultrasonic irradiation time, ultrasonic energy and amplitude. Ultrasonic frequency was constant - $20 \mathrm{kHz}$. 


\section{INTERNATIONAL SYMPOSIUM "THE ENVIRONMENT AND THE INDUSTRY", SIMI 2017, PROCEEDINGS BOOK}

Four sonolysis systems were tested both for synthetic water and real surface treated water: direct sonolysis US, US $+\mathrm{H}_{2} \mathrm{O}_{2}$, US $+\mathrm{H}_{2} \mathrm{O}_{2}+\mathrm{Fe}$ (Fenton sonolysis), US + $\mathrm{H}_{2} \mathrm{O}_{2}+\mathrm{Fe}+\mathrm{UV}$ (low pressure mercury lamp $\lambda=250-400 \mathrm{~nm}$ ).

The variation domains of the main process parameters were as following: THMs concentrations $310 \div 3615 \mu \mathrm{g} / \mathrm{L}$, sonolysis time $1 \div 60 \mathrm{~min}$., ultrasonic energy $2 \times 10^{6}$ $\mathrm{J}-8 \times 10^{6} \mathrm{~J}$, ultrasonic amplitude $20 \div 80 \%$, oxidant dose $0.6 \div 2.1 \mathrm{~g} \mathrm{H}_{2} \mathrm{O}_{2} / \mathrm{L}$, catalyst dose $0.25 \div 2 \mathrm{mg} \mathrm{Fe}^{2+} / \mathrm{L}$.

\section{Results and Discussion}

\section{Sonolysis of synthetic solutions with THMs content}

Experimental tests were performed for synthetic solutions with $\mathrm{CHCl}_{3}, \mathrm{CHBr}_{3}$, $\mathrm{CHBrCl}_{2}$ in the following concentrations domain: $\mathrm{CHCl}_{3}=131-1536 \mu \mathrm{g} / \mathrm{L}, \mathrm{CHBr}_{3}=$ $71-827 \mu \mathrm{g} / \mathrm{L}, \mathrm{CHBrCl}_{2}=108-1252 \mu \mathrm{g} / \mathrm{L}, \mathrm{TTHMs}($ Total THMs) $=310-3615$ $\mu \mathrm{g} / \mathrm{L}$. Sonolysis time was $1 \div 60 \mathrm{~min}$. Ultrasonic energy field varied in the range of 2 $\div 8 \times 10^{6}$ Joule and waves amplitudes were between $25 \div 80 \%$.

The influence of the above mentioned experimental parameters was determinated (Tables 1 - 4).

Residual concentrations of THMs species were measured and removal efficiencies were calculated for each one and for total content (Tables 1 - 4 and Figures 3 - 5) .

Regarding the influence of ultrasonic irradiation time, sonolysis time between $30-$ $60 \mathrm{~min}$. leads to total residual THMs $\leq 100 \mu \mathrm{g} / \mathrm{L}$ (below admitted limit).

Fig. 3 shows that $78 \%$ is maximum removal efficiency of total THMs and $\mathrm{CHCl}_{3}$ is the most removable THM ( $86 \%$ for $60 \mathrm{~min}$. irradiation time).

Table 1. The influence of sonolysis time to remanent THMs concentrations

\begin{tabular}{|c|c|c|c|c|c|}
\hline \multirow[t]{2}{*}{ Sample } & \multirow{2}{*}{$\begin{array}{l}\text { Time, } \\
\min \end{array}$} & \multicolumn{3}{|c|}{$\begin{array}{c}\text { Residual THMs } \\
\text { concentrations, } \mu \mathrm{g} / \mathrm{L}\end{array}$} & \multirow{2}{*}{$\begin{array}{c}\text { Residual } \Sigma \mathrm{THMs} \\
\text { concentrations, } \\
\mu \mathrm{g} / \mathrm{L}\end{array}$} \\
\hline & & $\mathrm{CHCl}_{3}$ & $\mathrm{CHBr}_{3}$ & $\mathrm{CHBrCl}_{2}$ & \\
\hline T1 & 1 & 94 & 49 & 73 & 216 \\
\hline $\mathrm{T} 2$ & 5 & 90 & 51 & 77 & 218 \\
\hline $\mathrm{T} 3$ & 15 & 58 & 50 & 53 & 161 \\
\hline $\mathrm{T} 4$ & 30 & 31 & 37 & 32 & 100 \\
\hline T5 & 45 & 29 & 33 & 28 & 90 \\
\hline T6 & 60 & 14 & 23 & 15 & 52 \\
\hline
\end{tabular}

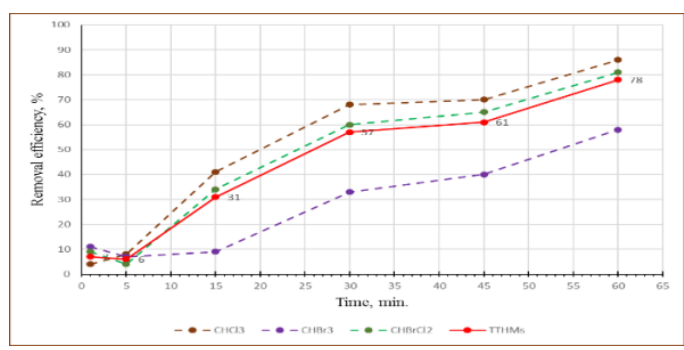

Figure 3. The influence of sonolysis time to THMs removal efficiencies 


\section{INTERNATIONAL SYMPOSIUM "THE ENVIRONMENT AND THE INDUSTRY", SIMI 2017, PROCEEDINGS BOOK}

Concerning the influence of initial THMs concentration, for the same irradiation time, energy and amplitude the lowest residual THMs concentration was for sample C1 having THMs initial concentration $310 \mu \mathrm{g} / \mathrm{L}$. Over this initial value the sonolysis process is not efficient in the selected operational conditions.

Table 2. The influence of initial THMs concentrations on residual organic content

\begin{tabular}{|c|c|c|c|c|c|c|c|c|}
\hline \multirow[t]{2}{*}{ Sample } & \multicolumn{3}{|c|}{$\begin{array}{c}\text { Initial THMs } \\
\text { concentrations, } \\
\mu \mathrm{g} / \mathrm{L}\end{array}$} & \multirow{2}{*}{$\begin{array}{c}\text { Initial } \\
\Sigma \text { THMs } \\
\text { conc., } \\
\mu \mathrm{g} / \mathrm{L}\end{array}$} & \multicolumn{3}{|c|}{$\begin{array}{c}\text { Residual THMs } \\
\text { concentrations, } \\
\mu \mathrm{g} / \mathrm{L}\end{array}$} & \multirow{2}{*}{$\begin{array}{l}\text { Residual } \\
\Sigma \text { THMs } \\
\text { conc., } \\
\mu \mathrm{g} / \mathrm{L}\end{array}$} \\
\hline & $\mathrm{CHCl}_{3}$ & $\mathrm{CHBr}_{3}$ & $\mathrm{CHBrCl}_{2}$ & & $\mathrm{CHCl}_{3}$ & $\mathrm{CHBr}_{3}$ & $\mathrm{CHBrCl}_{2}$ & \\
\hline $\mathrm{C} 1$ & 131 & 71 & 108 & 310 & 12.9 & 23.9 & 12.5 & 49.3 \\
\hline $\mathrm{C} 2$ & 237 & 135 & 196 & 568 & 52.5 & 84.9 & 57.2 & 194.6 \\
\hline C3 & 607 & 307 & 468 & 1382 & 144 & 147 & 133 & 424 \\
\hline $\mathrm{C} 4$ & 1048 & 531 & 820 & 2399 & 165 & 225 & 162 & 552 \\
\hline $\mathrm{C} 5$ & 1536 & 827 & 1252 & 3615 & 294 & 387 & 295 & 976 \\
\hline
\end{tabular}

The lowest value of total THMs residual content was determined for the highest value of ultrasonic energy (sample E4).

Regarding the influence of ultrasonic energy. Maximum efficiency for total THMs removal was $91 \%$ and bromoform has the lower value $-86 \%$.

Table 3. The influence of ultrasonic energy to residual THMs content

\begin{tabular}{|c|c|c|c|c|c|}
\hline \multirow[t]{2}{*}{ Sample } & \multirow{2}{*}{$\begin{array}{l}\text { Energy, } \\
\mathrm{J}\end{array}$} & \multicolumn{3}{|c|}{$\begin{array}{c}\text { Residual THMs concentrations, } \\
\mu \mathrm{g} / \mathrm{L}\end{array}$} & \multirow{2}{*}{$\begin{array}{c}\text { Residual } \Sigma \text { THMs } \\
\text { concentrations, } \\
\mu \mathrm{g} / \mathrm{L}\end{array}$} \\
\hline & & $\mathrm{CHCl}_{3}$ & $\mathrm{CHBr}_{3}$ & $\mathrm{CHBrCl}_{2}$ & \\
\hline E1 & $2 \times 10^{6}$ & 26.3 & 35.5 & 25.4 & 87.2 \\
\hline E2 & $4 \times 10^{6}$ & 12.9 & 23.9 & 12.5 & 49.3 \\
\hline E3 & $6 \times 10^{6}$ & 11.3 & 17.4 & 10.4 & 39.1 \\
\hline E4 & $8 \times 10^{6}$ & 9.7 & 10.2 & 6.9 & 26.8 \\
\hline \multicolumn{6}{|c|}{$\begin{array}{c}\Sigma \mathrm{THMs}=310 \mu \mathrm{g} / \mathrm{L}\left(\mathrm{CHCl}_{3}=131 \mu \mathrm{g} / \mathrm{L}, \mathrm{CHBr}_{3}=71 \mu \mathrm{g} / \mathrm{L},\right. \\
\left.\mathrm{CHBrCl}_{2}=108 \mu \mathrm{g} / \mathrm{L}\right), \text { Time }=60 \mathrm{~min} ., \text { Amplitude }=25 \%\end{array}$} \\
\hline
\end{tabular}

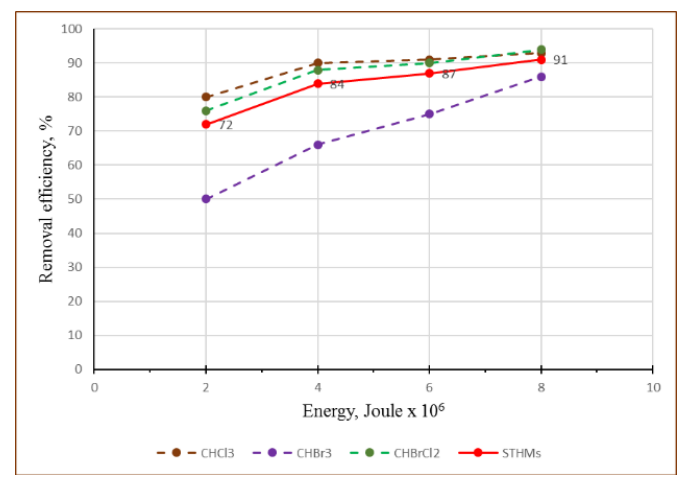

Figure 4. The influence of ultrasonic energy to THMs removal efficiencies 


\section{INTERNATIONAL SYMPOSIUM "THE ENVIRONMENT AND THE INDUSTRY", SIMI 2017, PROCEEDINGS BOOK}

From the point of view of the influence of ultrasonic waves amplitude, the increase of ultrasonic amplitude has not a significant influence on residual THMs concentrations, which were in the domain of $26-30 \mu \mathrm{g} / \mathrm{L}$.

Table 4. The influence of ultrasonic waves amplitude on residual THMs concentrations

\begin{tabular}{|c|c|c|c|c|c|}
\hline \multirow[t]{2}{*}{ Sample } & \multirow{2}{*}{$\begin{array}{l}\text { Amplitude, } \\
\%\end{array}$} & \multicolumn{3}{|c|}{$\begin{array}{c}\text { Residual THMs } \\
\text { concentrations, } \mu \mathrm{g} / \mathrm{L}\end{array}$} & \multirow{2}{*}{$\begin{array}{c}\text { Residual } \Sigma \text { THMs } \\
\text { concentrations, } \\
\mu \mathrm{g} / \mathrm{L}\end{array}$} \\
\hline & & $\mathrm{CHCl}_{3}$ & $\mathrm{CHBr}_{3}$ & $\mathrm{CHBrCl}_{2}$ & \\
\hline A1 & 25 & 9.7 & 10.2 & 6.9 & 26.8 \\
\hline A2 & 40 & 9.9 & 11 & 7.2 & 28.1 \\
\hline A3 & 60 & 8.9 & 9.7 & 7.5 & 26.1 \\
\hline A4 & 80 & 10.5 & 11.8 & 8.1 & 30.4 \\
\hline \multicolumn{6}{|c|}{$\begin{aligned} \Sigma \mathrm{THMs} & =310 \mu \mathrm{g} / \mathrm{L}\left(\mathrm{CHCl}_{3}=131 \mu \mathrm{g} / \mathrm{L}, \mathrm{CHBr}_{3}=71 \mu \mathrm{g} / \mathrm{L},\right. \\
\left.\mathrm{CHBrCl}_{2}=108 \mu \mathrm{g} / \mathrm{L}\right), \text { Time }=60 \mathrm{~min} ., \text { Energy } & =8 \times 10^{6} \mathrm{~J}\end{aligned}$} \\
\hline
\end{tabular}

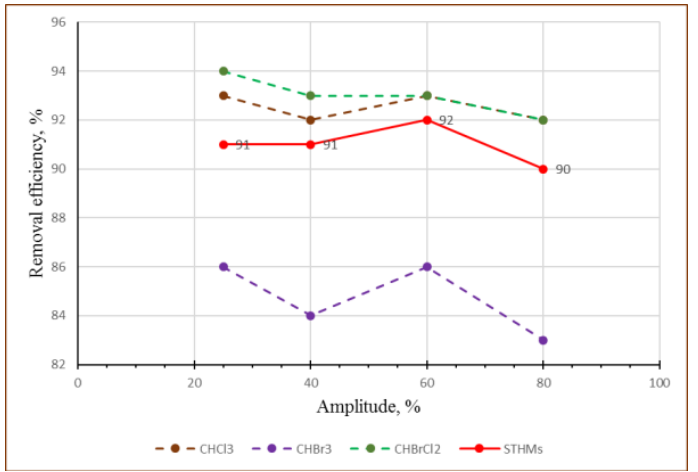

Figure 5. The influence of ultrasonic amplitude to removal efficiency of THMs

This tests confirm that bromoform had the lower removal efficiency (83\% for the maximum amplitude of $80 \%$ ).

Sonolysis of real drinking water with THMs content

In case of real drinking water which was pretreated by coagulation - flocculation ( 2 $\mathrm{mg} \mathrm{Al} / \mathrm{L}$ dose, 10 minutes stirring), flocculation with a flocculant based on starch and acrylamide (containing silver) $0.1 \%$ d.wt., $2 \mathrm{~mL} / \mathrm{L}$ dose, TTHMs content was $\sim 350$ $\mu \mathrm{g} / \mathrm{L}$. These reagent doses and reaction times were established to be optimal based on previous research experiments (only the reaction time was halved).

The best results for the sonolysis tests were obtained in the following experimental conditions (Table 5):

- direct sonolysis: $\mathrm{pH} 7$, time 30 min., energy $8 \times 10^{6} \mathrm{~J}$, amplitude $25 \%$;

- hybrid sonolysis $\mathrm{US}+\mathrm{H}_{2} \mathrm{O}_{2}$ : similar with direct sonolysis $+1,7 \mathrm{~g} \mathrm{H}_{2} \mathrm{O}_{2} / \mathrm{L}$;

- hybrid sonolysis $\mathrm{US}+\mathrm{H}_{2} \mathrm{O}_{2}+\mathrm{Fe}$ : similar with previous system $+1 \mathrm{mg} \mathrm{Fe} / \mathrm{L}$;

- hybrid sonolysis $\mathrm{US}+\mathrm{H}_{2} \mathrm{O}_{2}+\mathrm{Fe}+\mathrm{UV}$ : $\mathrm{pH} 7$, sonolysis time $30 \mathrm{~min}$., UV irradiation time $30 \mathrm{~min}$., $1,7 \mathrm{~g} \mathrm{H}_{2} \mathrm{O}_{2} / \mathrm{L}, 1 \mathrm{mg} \mathrm{Fe} / \mathrm{L}$, energy $8 \times 10^{6} \mathrm{~J}$, amplitude $25 \%$, iron catalyst 


\section{INTERNATIONAL SYMPOSIUM "THE ENVIRONMENT AND THE INDUSTRY", SIMI 2017, PROCEEDINGS BOOK}

and oxidant have put together in the photolytic reactor, after direct sonolysis phase.

Table 5. THMs removal efficiencies in different sonolysis systems

\begin{tabular}{c|ccccc}
\hline \multirow{2}{*}{ No. } & \multirow{2}{*}{ Sonolysis system } & \multicolumn{3}{|c}{$\eta \mathrm{THM}, \%$} & \multirow{2}{*}{ TTHM, \% } \\
\cline { 3 - 5 } & & $\mathrm{CHCl}_{3}$ & $\mathrm{CHBr}_{3}$ & $\mathrm{CHBrCl}_{2}$ & \\
\hline 1 & $\mathrm{US}$ & 70 & 48 & 65 & 56 \\
2 & $\mathrm{US}+\mathrm{H}_{2} \mathrm{O}_{2}$ & 70 & 51 & 66 & 59 \\
3 & $\mathrm{US}+\mathrm{H}_{2} \mathrm{O}_{2}+\mathrm{Fe}$ & 82 & 67 & 80 & 73 \\
4 & $\mathrm{US}+\mathrm{H}_{2} \mathrm{O}_{2}+\mathrm{Fe}+\mathrm{UV}$ & 63 & 66 & 59 & 63 \\
\hline
\end{tabular}

\section{Conclusions}

Experimental results showed the evolution of THMs removal depending on sonolysis system: direct sonolysis (US) $56 \%<$ sonolysis and hidrogen peroxide (US $+\mathrm{H}_{2} \mathrm{O}_{2}$ ) $59 \%<$ foto Fenton sonolysis (US $+\mathrm{H}_{2} \mathrm{O}_{2}+\mathrm{Fe}+\mathrm{UV}$ ) $63 \%<$ Fenton sonolysis (US + $\left.\mathrm{H}_{2} \mathrm{O}_{2}+\mathrm{Fe}\right) 73 \%$ emphasizing that bromoform are more difficult to remove compared to other.

\section{Acknowledgements}

The research was founded by a grant of the Romanian National Authority for Scientific Research - PN2: 64/2012 -Project FLAMIR and Program Nucleu - Project PN 09130316.

\section{References}

Ashokkumar, T 2011, 'The characterization of acoustic cavitation bubbles - An overview', Ultrasonic Sonochemistry, vol. 18, pp. $864-872$.

Mahamuni, N \& Adewuyi, YG 2010, 'Advanced oxidation processes (AOPs) involving ultrasound for wastewater treatment: A review with emphasis on cost estimation', Ultrasonic Sonochemistry, vol. 17, pp. 990 - 1003.

Naddeo, V \& Belgiornao, V 2007, 'Behaviour of natural organic matter during ultrasonic irradiation', Desalination, vol. 210, pp. 175 - 182.

Joseph, CG, Puma, GL, Bono, A, Krismaiah, D 2009, 'Sonophotocatalysis in advanced oxidation process: A short review', Ultrasonic Sonochemistry, vol. 16 , pp. $583-589$.

Shemmer, H \& Narkis, N 2005, 'Trihalomethanes aqueous solutions sono oxidation', Water Research, vol. 39, pp. $2704-2710$.

Stefanescu, M, Cosma, C, Cristea, I, Ionescu, I \& Bumbac, C 2015, 'Degradation of natural organic matter from Surface Water Using Sonolysis', International Symposium The Environment and Industry, SIMI 2015, National Research and Development Institute for Industrial Ecology ECOIND, pp. 47-54. 